\title{
Characteristics and Kinetics of Ring-opening Polymerization of $\varepsilon$-Caprolactone Initiated by Lanthanide Tris(2,4,6-trimethylphenolate)s
}

\author{
Ling FAN, Lifang ZHANG, and Zhiquan SHEN ${ }^{\dagger}$ \\ Institute of Polymer Science, Zhejiang University, Hangzhou 310027, People's Republic of China
}

(Received June 16, 2003; Accepted October 30, 2003)

\begin{abstract}
Novel single-component rare earth phenolate catalyst-lanthanide tris(2,4,6-trimethylphenolate)s $\left[\mathrm{Ln}(\mathrm{OTMP})_{3}\right]$ initiated ring-opening polymerization of $\varepsilon$-Caprolactone $(\mathrm{CL})$. The effects of polymerization conditions, such as rare earth element, solvent, ligand, monomer and catalyst concentration, as well as reaction temperature and time on the polymerization have been investigated. Kinetics study indicates that the polymerization is of first order with respect to monomer and to initiator concentration, and the overall activation energy amounts to $58.7 \mathrm{~kJ} / \mathrm{mol} .{ }^{1} \mathrm{HNMR}$ spectrum analyses of PCL demonstrates that the polymerization of CL proceeds through acyl-oxygen bond cleavage. KEY WORDS Lanthanide Tris(2,4,6-trimethylphenolate)s / Ring-opening Polymerization / $\varepsilon$-Caprolactone / Kinetics /
\end{abstract}

Biodegradable and biocompatible polyesters such as polycaprolactone (PCL) and polylactide are of great interest for their applications in the medical, pharmaceutical, and agricultural fields. ${ }^{1,2}$ The recent research focus is on the ring-opening polymerization method for their synthesis using metal catalysts, especially rare earth catalysts which form an emerging and promising class of polymerization initiators. ${ }^{3-5}$ Our group has dedicated to develop rare earth catalysts with low toxicity and high efficiency for lactone and lactide polymerization. ${ }^{6,7}$ Recently single-component rare earth catalysts have been developed for ringopening polymerization of CL. ${ }^{8-10}$ In this paper, we describe a novel single-component rare earth catalyst for the ring-opening polymerization of CL, namely lanthanide tris(2,4,6-trimethylphenolate)s $\left(\left[\mathrm{Ln}(\mathrm{OTMP})_{3}\right]\right.$, Scheme 1$)$. The characteristics, kinetics and mechanism of the polymerization initiated by $\mathrm{Ln}(\mathrm{OTMP})_{3}$ have been reported.

\section{EXPERIMENTAL}

\section{Materials}

CL (from Mitsubishi) was dried over calcium hydride, distilled under reduced pressure, and stored

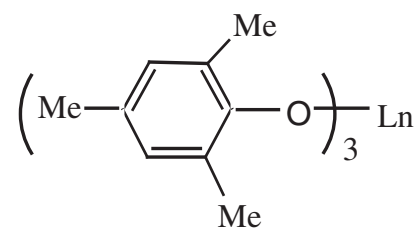

Scheme 1. The structure of $\mathrm{Ln}(\mathrm{OTMP})_{3}(\mathrm{Ln}=\mathrm{La}, \mathrm{Nd}$, $\mathrm{Sm}, \mathrm{Y}, \mathrm{Er})$.

\footnotetext{
${ }^{\dagger}$ To whom correspondence should be addressed.
}

over $4 \AA$ molecular sieves. Toluene and tetrahydrofuran were dried by refluxing over benzophenone-Na complex and distilled under nitrogen atmosphere just prior to use. $\mathrm{CH}_{2} \mathrm{Cl}_{2}$ and $\mathrm{CCl}_{4}$ were dried by refluxing over $\mathrm{P}_{2} \mathrm{O}_{5}$ and distilled as toluene. Rare earth oxides (from Shanghai Yaolong Factory, 99.99\%) were used as received.

\section{Preparation of Catalysts}

Anhydrous rare earth chloride and single-component rare earth phenolates were prepared according to the methods in refs. 11 and 12 , respectively.

\section{Polymerization}

All polymerizations were carried out in $20 \mathrm{~mL}$ glass ampoules previously flamed and purged by dry nitrogen. Solvent, monomer and initiator were added to the ampoule successively by syringe. The polymerization was terminated by methanol containing $5 \% \mathrm{HCl}$. The polymer was washed with methanol several times and then dried under vacuum to constant weight at $40^{\circ} \mathrm{C}$.

\section{Measurements}

Viscosity measurements were carried out in dimethylformamide with an Ubbelohde viscometer at $30^{\circ} \mathrm{C}$. Viscosity average molecular weight $\left(\bar{M}_{\nu}\right)$ was calculated from the equation: ${ }^{13}[\eta]=1.94 \times$ $10^{-4} \bar{M}_{\nu}^{0.73}$. The number average molecular weight $\left(\bar{M}_{n}\right)$ and molecular weight distribution (MWD) were determined by gel permeation chromatograph (Waters 150) in THF at $25^{\circ} \mathrm{C}$ and calibrated with polystyrene standards. Differential scanning calorimetric measurement was conducted on a Perkin-Elmer Pyris 1 at a heating rate of $10^{\circ} \mathrm{C} / \mathrm{min}$ from $0^{\circ} \mathrm{C}$ to $100^{\circ} \mathrm{C}$. The crystallinity was calculated from the equation: $X_{\mathrm{c}}=\Delta H_{\mathrm{f}} / \Delta H_{\mathrm{f}}{ }^{*}$, where $\Delta H_{\mathrm{f}}{ }^{*}$ is the melt enthalpy 
Table I. Effect of rare earth element on the polymerization

\begin{tabular}{crrrrr}
\hline $\mathrm{Ln}(\mathrm{OTMP})_{3}$ & {$[\mathrm{CL}] /[\mathrm{Ln}]$} & $\mathrm{Conv}(\%)$ & $\bar{M}_{v} \times 10^{-4}$ & $\bar{M}_{n} \times 10^{-4}$ & $\mathrm{MWD}$ \\
\hline $\mathrm{La}$ & 800 & 100 & 6.81 & 6.05 & 1.71 \\
& 1000 & 100 & 7.75 & 7.47 & 1.60 \\
$\mathrm{Nd}$ & 800 & 50.4 & 4.85 & 4.07 & 1.65 \\
& 1000 & 42.5 & 4.91 & 4.26 & 1.58 \\
$\mathrm{Sm}$ & 800 & 98.6 & 3.79 & 3.65 & 1.61 \\
& 1000 & 92.4 & 5.27 & 4.97 & 1.57 \\
$\mathrm{Er}$ & 800 & 11.7 & 2.31 & 2.11 & 1.55 \\
& 1000 & 10.1 & 2.35 & 2.23 & 1.50 \\
$\mathrm{Y}$ & 800 & 6.8 & 0.94 & - & - \\
& 1000 & 8.1 & 1.42 & - & - \\
\hline
\end{tabular}

Conditions: $[\mathrm{CL}]=2 \mathrm{~mol} / \mathrm{L}, 60^{\circ} \mathrm{C}, 1 \mathrm{~h}$, toluene

Table II. Influence of solvent on the polymerization

\begin{tabular}{cclll}
\hline Solvent & Conv $(\%)$ & $\bar{M}_{\nu} \times 10^{-4}$ & $\bar{M}_{n} \times 10^{-4}$ & MWD \\
\hline Toluene & 100 & 7.75 & 7.47 & 1.60 \\
$\mathrm{CCl}_{4}$ & 100 & 4.53 & 4.21 & 1.54 \\
$\mathrm{THF}$ & 16.0 & 1.08 & 0.98 & 1.91 \\
$\mathrm{CH}_{2} \mathrm{Cl}_{2}$ & 10.3 & 0.95 & 0.82 & 1.93 \\
\hline
\end{tabular}

Conditions: $\mathrm{La}(\mathrm{OTMP})_{3},[\mathrm{CL}]=2 \mathrm{~mol} / \mathrm{L}, 60^{\circ} \mathrm{C},[\mathrm{CL}] /[\mathrm{La}]$ $=1000,1 \mathrm{~h}$

of a $100 \%$ crystalline PCL $(15.4 \mathrm{~kJ} / \mathrm{mol})$, and $\Delta H_{\mathrm{f}}$ is that of a given PCL sample to be measured. ${ }^{1} \mathrm{H}$ NMR spectrum was recorded on a Bruker Avance DMX500 spectrometer in $\mathrm{CDCl}_{3}$ at room temperature with tetramethylsilane as the internal reference.

\section{RESULTS AND DISCUSSION}

\section{Characteristics of the polymerization}

The polymerization of CL was carried out with five different rare earth phenolates (Table I). It is found that the polymerization activity of the compounds has following order: $\mathrm{La} \approx \mathrm{Sm}>\mathrm{Nd}>\mathrm{Er}>\mathrm{Y}$. $\mathrm{La}(\mathrm{OTMP})_{3}$ exhibited the highest activity and prepared PCL with higher molecular weight $(7.47 \times$ $10^{4}$ ) at $60^{\circ} \mathrm{C}$ in $1 \mathrm{~h}$. The influence of different organic solvents on the polymerization of $\mathrm{CL}$ with $\mathrm{La}(\mathrm{OTMP})_{3}$ is summarized in Table II. It can be seen that $\mathrm{La}(\mathrm{OTMP})_{3}$ shows higher catalytic activity and prepares higher molecular weight PCL with narrower MWD in non-polar solvent than in polar solvent. Toluene is a proper solvent for the polymerization of CL.

The ligand attached to lanthanum affects polymerization significantly as shown in Table III. Four lanthanum phenolates were used as initiators for the polymerization of CL: lanthanum tris(2,4,6-trimethylphenolate) $\left[\mathrm{La}(\mathrm{OTMP})_{3}\right]$, lanthanum tris(2,6-di-tertbutyl-4-methylphenolate) [La(ODTBMP $\left.)_{3}\right]$, lanthanum tris(2,6-dimethyl phenolate) $\left[\mathrm{La}(\mathrm{ODMP})_{3}\right]$ and lanthanum tris(4-tert-butylphenolate) $\left[\mathrm{La}(\mathrm{OTBP})_{3}\right]$. The data show that both polymerizations initiated by $\mathrm{La}(\mathrm{OTMP})_{3}$ and $\mathrm{La}(\mathrm{ODTBMP})_{3}$ respectively can pro-
Table III. Effect of ligand on the polymerization

\begin{tabular}{lcccc}
\hline Initiator & Conv $(\%)$ & $\bar{M}_{v} \times 10^{-4}$ & $\bar{M}_{n} \times 10^{-4}$ & MWD \\
\hline $\mathrm{La}(\text { OTMP })_{3}$ & 100 & 7.75 & 7.47 & 1.60 \\
$\mathrm{La}(\text { ODTBMP })_{3}$ & 100 & 5.49 & 3.52 & 3.12 \\
$\mathrm{La}(\mathrm{ODMP})_{3}$ & 74.1 & 4.32 & 3.97 & 1.60 \\
$\mathrm{La}(\mathrm{OTBP})_{3}$ & 71.0 & 4.75 & 3.25 & 1.58 \\
\hline
\end{tabular}

Conditions: $[\mathrm{CL}]=2 \mathrm{~mol} / \mathrm{L}, 60^{\circ} \mathrm{C},[\mathrm{CL}] /[\mathrm{La}]=1000,1 \mathrm{~h}$, toluene

Table IV. Ring-opening polymerization of $\varepsilon$-CL with $\mathrm{La}(\mathrm{OTMP})_{3}$

\begin{tabular}{lcccccc}
\hline No. & $\begin{array}{c}{[\mathrm{M}]} \\
(\mathrm{mol} / \mathrm{L})\end{array}$ & $\begin{array}{c}{[\mathrm{CL}] /[\mathrm{La}]} \\
(\text { molar ratio })\end{array}$ & $\begin{array}{c}\text { Conv } \\
(\%)\end{array}$ & $\bar{M}_{v} \times 10^{-4}$ & $\bar{M}_{n} \times 10^{-4}$ & MWD \\
\hline 1 & 1.0 & 1000 & 52.4 & 3.01 & 2.82 & 1.46 \\
2 & 1.5 & 1000 & 85.1 & 5.25 & 4.79 & 1.54 \\
3 & 2.0 & 1000 & 100 & 7.75 & 7.47 & 1.60 \\
4 & 2.5 & 1000 & 99.4 & 6.21 & 6.13 & 1.66 \\
5 & 3.0 & 1000 & 96.9 & 4.56 & 4.50 & 1.72 \\
6 & 4.0 & 1000 & 87.0 & 4.12 & 4.01 & 1.80 \\
7 & 2.0 & 600 & 100 & 3.96 & 3.75 & 1.92 \\
8 & 2.0 & 800 & 100 & 6.38 & 6.12 & 1.73 \\
9 & 2.0 & 1200 & 82.1 & 5.95 & 5.77 & 1.52 \\
\hline
\end{tabular}

Conditions: $60^{\circ} \mathrm{C}, 1 \mathrm{~h}$, toluene

ceed up to $100 \%$ conversion in an hour, which indicate that they have higher catalytic activity than the other two. The reason for different catalytic activities and molecular weights with the four compounds may be owing to the different electron donating effect of substituents and their positions of the phenyl ring. $\mathrm{La}(\mathrm{OTMP})_{3}$ prepared PCL with narrower MWD (1.60) than $\mathrm{La}(\mathrm{ODTBMP})_{3}$ did (3.12), which is possibly due to the much more transesterification in $\mathrm{La}(\mathrm{ODTBMP})_{3}$ system. It can be concluded that $\mathrm{La}(\mathrm{OTMP})_{3}$ is preferable for the polymerization of CL under the conditions used.

The influences of monomer concentration and monomer/initiator (CL/La) molar ratio on polymerization of CL were examined as shown in Table IV. The data show that both monomer conversion and molecular weight of PCL increase with the rise of monomer concentration till $2 \mathrm{~mol} / \mathrm{L}$, then the molecular weight of PCL begins to drop over that concentration. The molecular weight of PCL reaches summit at the molar ratio of 1000. Table $\mathrm{V}$ gives the results of the effects of reaction temperature and duration on polymerization of CL. It can be concluded that the optimum conditions for CL polymerization initiated with $\mathrm{La}(\mathrm{OTMP})_{3}$ are as follows: $[\mathrm{CL}]=2 \mathrm{~mol} / \mathrm{L},[\mathrm{CL}] /$ $[\mathrm{La}]=1000,60^{\circ} \mathrm{C}, 1 \mathrm{~h}$, in toluene.

DSC measurement of the PCL sample obtained by $\mathrm{La}(\mathrm{OTMP})_{3}$ displays a single peak at $68.4{ }^{\circ} \mathrm{C}$, and the sample has a $66.5 \%$ crystallinity. The unimodal GPC curve (Figure 1) indicates that only one active species presented in the polymerization system. 
Table V. Effect of reaction temperature and time on the polymerization

\begin{tabular}{rcccccc}
\hline No. & $\begin{array}{c}\text { Temp } \\
\left({ }^{\circ} \mathrm{C}\right)\end{array}$ & $\begin{array}{c}\text { Time } \\
(\mathrm{min})\end{array}$ & $\begin{array}{c}\text { Conv } \\
(\%)\end{array}$ & $\bar{M}_{v} \times 10^{-4}$ & $\bar{M}_{n} \times 10^{-4}$ & MWD \\
\hline 1 & 40 & 60 & 39.6 & 3.54 & 3.02 & 1.42 \\
2 & 50 & 60 & 57.9 & 5.68 & 5.30 & 1.51 \\
3 & 60 & 60 & 100 & 7.75 & 7.47 & 1.60 \\
4 & 70 & 60 & 100 & 6.98 & 7.07 & 1.69 \\
5 & 60 & 11 & 17.9 & 1.33 & 1.10 & 1.26 \\
6 & 60 & 20 & 36.8 & 3.47 & 3.17 & 1.28 \\
7 & 60 & 30 & 53.5 & 4.29 & 4.15 & 1.38 \\
8 & 60 & 40 & 80.2 & 5.53 & 5.16 & 1.45 \\
9 & 60 & 50 & 91.6 & 6.91 & 6.50 & 1.53 \\
10 & 60 & 80 & 100 & 7.40 & 6.93 & 1.70 \\
\hline
\end{tabular}

Conditions: $[\mathrm{CL}]=2 \mathrm{~mol} / \mathrm{L},[\mathrm{CL}] /[\mathrm{La}]=1000$, toluene

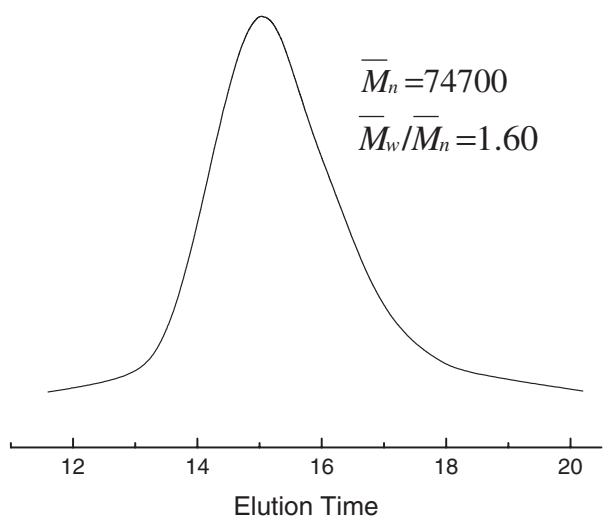

Figure 1. GPC curve of PCL (No. 3 Table V).

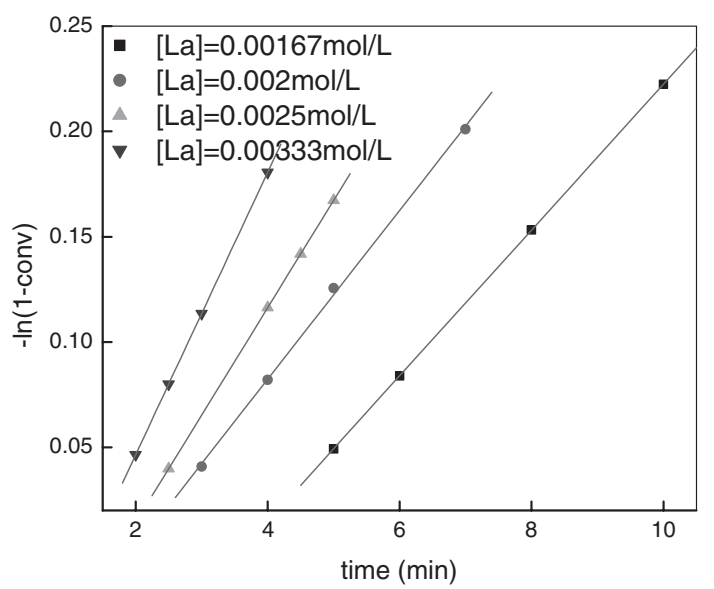

Figure 2. The dependence of monomer consumption on the polymerization time Conditions: $[\mathrm{CL}]=2 \mathrm{~mol} / \mathrm{L}, 60^{\circ} \mathrm{C}$, toluene.

\section{Kinetic Behavior}

The kinetics of CL polymerization with $\mathrm{La}(\mathrm{OTMP})_{3}$ in toluene was investigated by weight method. The polymerization reaction was terminated at low conversion $(<20 \%)$.

The dependence of monomer consumption on the polymerization time at four different catalyst concentrations is shown in Figure 2, which illustrates that the
Table VI. The slope of each plot in Figure 2

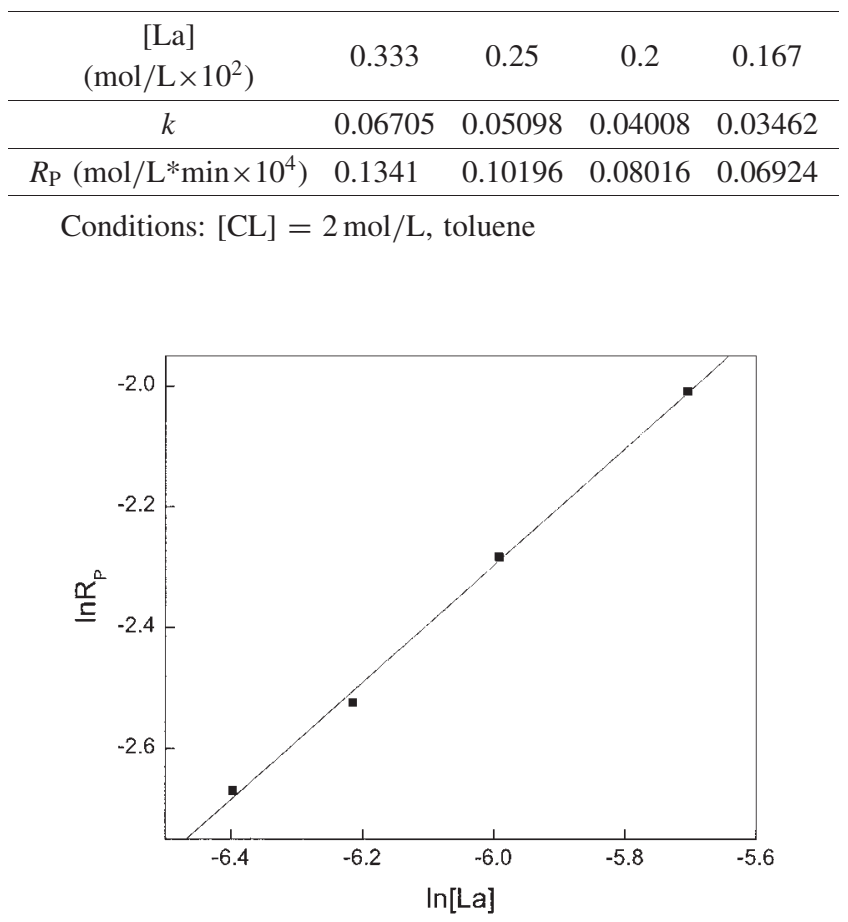

Figure 3. The relationship between $\ln R_{\mathrm{p}}$ and $\ln [\mathrm{La}]$.

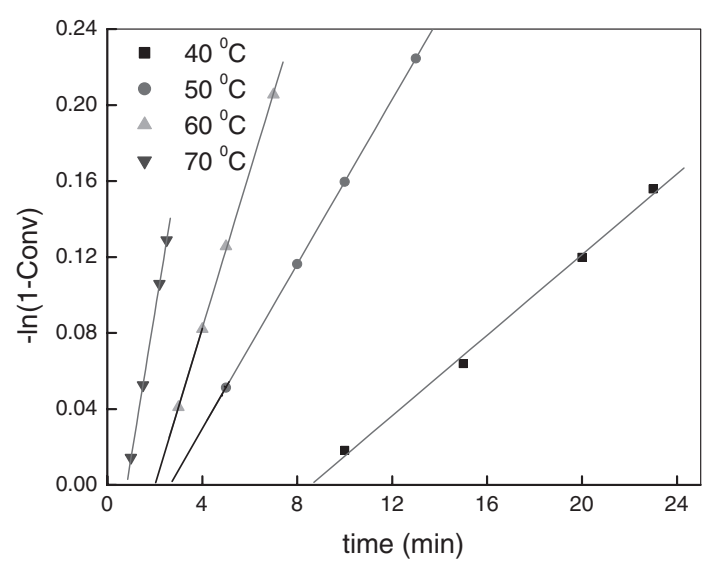

Figure 4. The dependence of monomer consumption on the polymerization time Conditions: $[\mathrm{CL}]=2 \mathrm{~mol} / \mathrm{L},[\mathrm{CL}] /[\mathrm{La}]=$ 1000 , toluene.

polymerization is of first order with respect to monomer concentration. From the plots in Figure 2, each slope was calculated and presented in Table VI. The plot of $\ln R_{\mathrm{p}} v s . \ln [\mathrm{La}]$ is a straight line with a slope of 0.96, as illustrated in Figure 3, indicating the polymerization is of first order with respect to catalyst concentration, too. Thus, the polymerization rate equation can be written as:

$$
R_{p}=k_{p}[M][C a t]
$$

Figure 4 presents the dependence of monomer consumption on the polymerization time at four different temperatures. According to Figure 4, Arrhenius plot of 


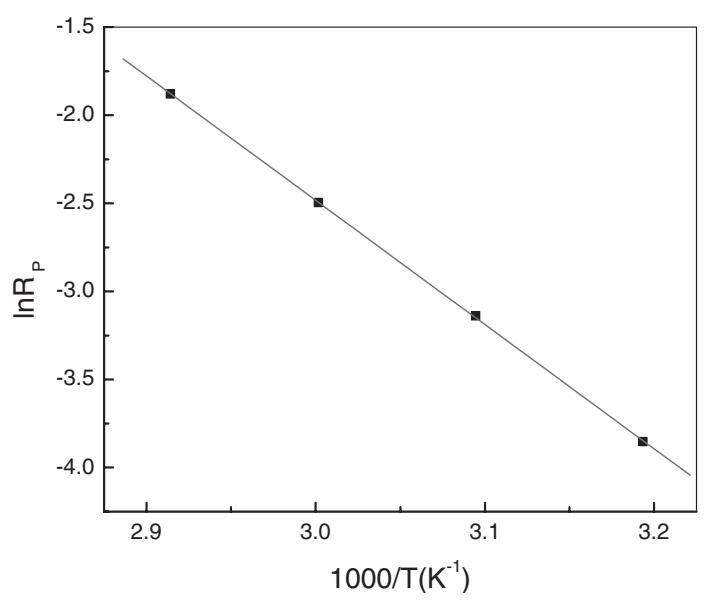

Figure 5. Correlation of $\ln R_{\mathrm{p}}$ with $1 / T$.

$\ln R_{\mathrm{p}}$ versus the reciprocal of absolute temperature of polymerization $(1 / T)$ gives a straight line in the range of temperature studied, as illustrated in Figure 5. The overall activation energy was found to be $58.7 \mathrm{~kJ} / \mathrm{mol}$.

\section{Mechanism Aspects}

The above solvent effect (Table II) indicates that the ring-opening polymerization of $\mathrm{CL}$ initiated by $\mathrm{Ln}(\mathrm{OTMP})_{3}$ prefers to proceed a coordination ionic mechanism process. To confirm the bond cleavage mode of the monomer, a PCL sample of low molecular weight terminated by isopropanol (containing $5 \% \mathrm{HCl}$ ) has been prepared for ${ }^{1} \mathrm{HNMR}$ analysis. Two ends of the polymer chain are: an acyl-isopropoxide - $\mathrm{COOCH}\left(\mathrm{CH}_{3}\right)_{2}$ group and a hydroxy-methylene $-\mathrm{CH}_{2} \mathrm{OH}$ group, respectively, which are confirmed by proton signals at $1.20 \mathrm{ppm}$ (doublet) for $\mathrm{H}^{\mathrm{a}}, 5.02$ (multiplet) for $\mathrm{H}^{\mathrm{b}}$ and 3.64 (triplet) for $\mathrm{H}^{\mathrm{f}}$ (Figure 6). This clearly demonstrates that CL monomer opening takes place through acyl-oxygen bond cleavage. The fact that no initiator residues of both

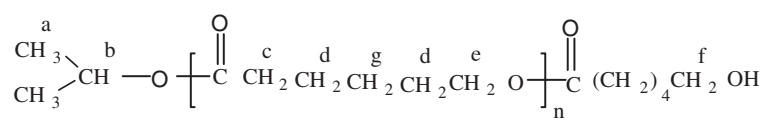

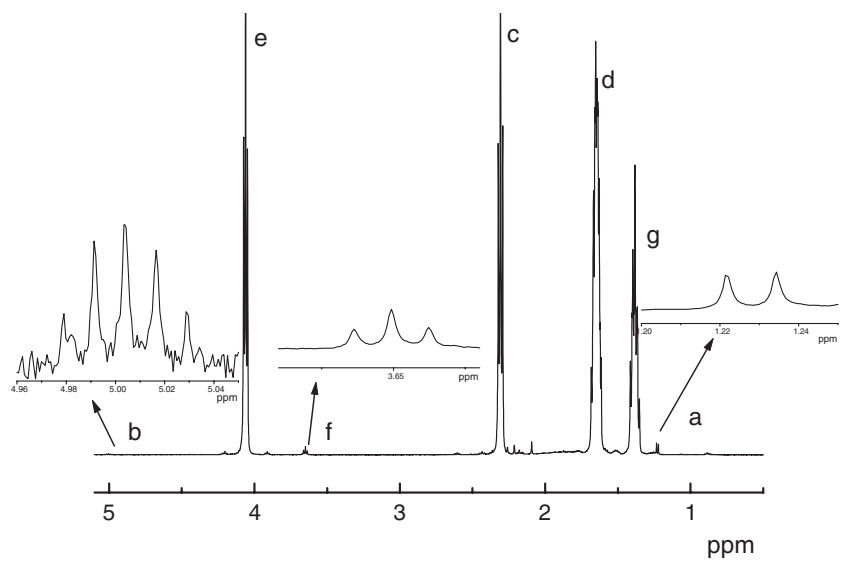

Figure 6. ${ }^{1} \mathrm{H}$ NMR of PCL terminated by isopropanol. PCL $\delta$ $(\mathrm{ppm}): \mathrm{H}^{\mathrm{a}}=1.20, \mathrm{H}^{\mathrm{b}}=5.02, \mathrm{H}^{\mathrm{c}}=2.31, \mathrm{H}^{\mathrm{d}}=1.64, \mathrm{H}^{\mathrm{e}}=4.06$, $\mathrm{H}^{\mathrm{f}}=3.64, \mathrm{H}^{\mathrm{g}}=1.40$.

rare earth metal and trimethylphenyl were found in the obtained PCL provides two possible monomer insertion modes: inserting into (1) Ln-O bond to develop an "anionic coordination" mechanism or (2) COOTMP (maybe carbonyl cationic) to develop a "cationic" mechanism. Our group has reported that Ln$\mathrm{O}$ side was the active center when $\mathrm{Ln}(\mathrm{ODTBMP})_{3}$ initiating CL or DTC polymerization. ${ }^{10,14}$ Considering the similarity of the two ligands of OTMP and ODTBMP., the same anionic coordination insertion mechanism occurs in this system. The isopropoxy group took the place of the trimethylphenoxy group when terminating the polymerization mixture with isopropanol in the presence of hydrochloric acid because of alkyl-ester group is more stable.

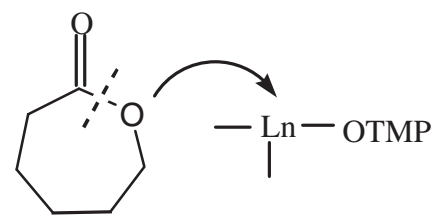

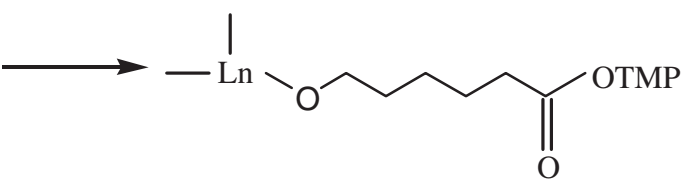

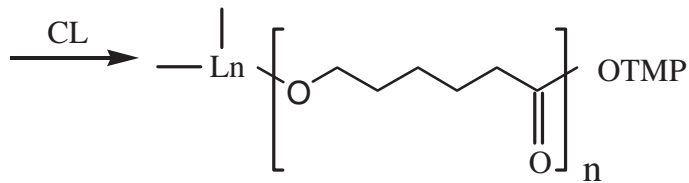

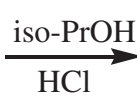<smiles>CCOCCCCCC(=O)OC(C)C</smiles>

Scheme 2. The mechanism of the polymerization. 
Acknowledgment. We are grateful for financial supports of the National Natural Science Foundation (Grant No. 20174033; 20254001), the Ministry of Science and Technology of China (Grant No. 1999064801) and the Committee of Science and Technology of Zhejiang Province.

\section{REFERENCES}

1. C. G. Pitt and A. Schindler, "Biodegradable and Delivery Systems for Contraception, Progress in Contraceptive Delivery Systems," In: H. Ese and V. O. Waa, (eds.), volume 1, MTP Press, Lancaster, England (1980a), p 17.

2. T. S. Pierre and E. Chiellini, J. Bioactive Compat. Polym., 2, 4 (1987)

3. H. R. Kricheldorf and I. Kreiser-Saunders, Polymer, 41, 3957 (2000).

4. S. Agarwal, C. Mast, K. Ddhnicke, and A. Greiner, Macromol. Rapid Commun. 21, 195 (2000).
5. H. Yasuda, J. Organomet. Chem. 647, 128 (2002).

6. Z. Q. Shen, X. H. Chen, Y. Q. Shen, and Y. F. Zhang, J. Polym. Sci., Polym. Chem. Ed., 32, 597 (1994).

7. Y. Q. Shen, Z. Q. Shen, Y. F. Zhang, and K. M. Yao, Macromolecules, 29, 8289 (1996).

8. Y. Q. Shen, Z. Q. Shen, F. Y. Zhang, and Y. F. Zhang, Polym. J., 27, 59 (1995).

9. Y. Q. Shen, Z. Q. Shen, and K. M. Yao, Macromolecules, 29, 3441 (1996).

10. J. Ling, Z. Q. Shen, and Q. H. Huang, Macromolecules, 34, 7613 (2001).

11. M. D. Taylor and C. P. Carter, J. Inorg. Nucl. Chem., 24, 387 (1962).

12. P. B. Hitchcock, M. F. Lappert, and A. Singh, J. Chem. Soc., Chem. Commun., 1499 (1983).

13. G. L. Brode and J. V. Koleske, J. Macromol. Sci., Chem., 6, 1109 (1972).

14. J. Ling and Z. Q. Shen, Macromol. Chem. Phys., 203, 735 (2002). 